\title{
Spatial Combination Modeling Framework of Saturation-Excess and Infiltration-Excess Runoff for Semihumid Watersheds
}

\author{
Pengnian Huang, ${ }^{1,2}$ Zhijia Li, $^{1,2}$ Cheng Yao,, ${ }^{1,2}$ Qiaoling Li, ${ }^{1,2}$ and Meichun Yan ${ }^{3}$ \\ ${ }^{1}$ College of Hydrology and Water Resources, Hohai University, Nanjing 210098, China \\ ${ }^{2}$ National Cooperative Innovation Center for Water Safety \& Hydro-Science, Hohai University, Nanjing 210098, China \\ ${ }^{3}$ School of Earth Science and Engineering, Hohai University, Nanjing 210098, China \\ Correspondence should be addressed to Cheng Yao; yaocheng@hhu.edu.cn
}

Received 5 October 2015; Revised 22 December 2015; Accepted 30 December 2015

Academic Editor: Jingfeng Wang

Copyright (C) 2016 Pengnian Huang et al. This is an open access article distributed under the Creative Commons Attribution License, which permits unrestricted use, distribution, and reproduction in any medium, provided the original work is properly cited.

\begin{abstract}
There exist two types of direct runoff generation mechanisms in semihumid watersheds: saturation-excess mechanism and infiltration-excess mechanism. It has always been a difficult problem for event hydrological simulation to distinguish the two types of runoff processes. Based on the concept of dominant runoff processes, combined with GIS and RS techniques, this paper proposed an event-based spatial combination modeling framework and built two spatial combination models (SCMs) accordingly. The CN parameter and topographic index, both of which are widely used in hydrological researches, are adopted by the SCM to divide the entire watershed into infiltration-excess dominated (IED) areas and saturation-excess dominated (SED) areas. Dongwan watershed was taken as an example to test the performances of infiltration-excess model, saturation-excess model, and SCM, respectively. The results of parameter optimization showed that the parameter values and state variables of SCM are much more realistic than those of infiltration-excess model and saturation-excess model. The more accurate the divisions of infiltration-excess and saturation-excess dominated areas, the more realistic the SCM parameter values. The simulation results showed that the performance of SCM was improved in both calibration and validation periods. The framework is useful for flood forecasting in semihumid watersheds.
\end{abstract}

\section{Introduction}

Floods are one of the most common natural hazards throughout the world. Therefore, as a crucial flood protection tool, flood simulation model has received increasing attention. In order to increase the model's predictive power, model realism is always considered as an important topic in the model development process [1-4]. As early as 1970, Nash and Sutcliffe stated that if it was hoped to use the model for watersheds without records, it was essential to obtain some guide to the realism of model parts and the accuracy of parameter values [5].

The physically based hydrological model is a powerful tool to reflect the physical reality of watershed hydrological response. However, it needs highly detailed and abundant data (e.g., high-resolution land use data, soil data, and groundwater data) to represent the hydrophysical processes. Such data are usually unavailable or difficult to obtain. In addition, due to the use of bottom-up approach, the physically based hydrological model is more applicable for small watersheds, which cannot meet the requirements of flood forecasting.

The conceptual hydrological model is more suitable for flood forecasting. The difficulty is that how to increase the realism and the predictive power of a conceptual model. The flexible model framework proposed recently is a useful way to configure a realistic conceptual model structure for a given watershed [6-8].

Traditionally, conceptual model cannot represent the heterogeneity and complexity of hydrological processes within a watershed. To solve this problem, Savenije proposed the spatially distributed conceptual structure using the flexible approach [9]. He believed that, among landscape factors, terrain factor is the most critical factor affecting runoff generation and routing, followed by vegetation factor and soil factor. He took a typical western European watershed as 
an example to elaborate his methodology. The watershed was divided into three parts: wetlands, hillslopes, and plateaus. Wetlands close to the rivers are dominated by saturationexcess runoff, hillslopes which are usually forested are dominated by lateral runoff, and plateaus are dominated by deep percolation, sometimes accompanied by infiltration-excess runoff. Gao et al. applied this methodology to the watershed of the upper Heihe River in China and found that the hillslope should be further subdivided into grassland and woodland [4]. For more researches, the reader is referred to [10-12].

Such frameworks are suitable for continuous simulation rather than event simulation. In the continuous simulation, evapotranspiration, and subsurface flow are important components, whereas in the event simulation, they can be ignored to some extent. Therefore, frameworks for continuous and event hydrological simulation should largely differ.

This study aims to develop a spatially distributed conceptual structure for flood event simulation. As is generally known, at the point scale, runoff generation can be represented exactly by differential equations [13]. However, at the watershed scale for flood simulation, the differential equations should be simplified into two runoff generation mechanisms: saturation-excess mechanism [14] and infiltrationexcess mechanism [15]. Saturation-excess runoff is dominant in humid areas and infiltration-excess runoff is dominant in arid and semiarid areas [16-19]. Nevertheless, in semihumid areas, there is no dominant runoff generation mechanism. In other words, saturation-excess and infiltration-excess runoff may exist simultaneously during a storm, which can be called mixed runoff generation.

Currently, conceptual saturation-excess runoff model is maturely developed and widely used. Flood forecasting using this type of model can meet the accuracy requirements in humid areas in China. On the contrary, great difficulties have hindered accurate forecasts of infiltration-excess runoff in arid and semiarid areas, which are mainly due to the lack of high-resolution observational data. Despite the problem of data shortage, the understanding of the processes of infiltration-excess runoff generation is still clear. However, in semihumid areas, there is no clear understanding of the mixed runoff generation, and the main difficulty is how to identify the saturation-excess and infiltration-excess runoff that coexist within a watershed.

The current popular mixed runoff models are constructed in the light of the vertical combination of saturation-excess module and infiltration-excess module, such as Sacramento model [20]. These mixed runoff models partly avoid the defects of single runoff models and are able to improve the forecast accuracies of flood events. However, their performances overly depend on parameter calibration and optimization. Consequently, the problem of identification of saturation-excess runoff and infiltration-excess runoff is not solved and the model realism is limited.

To some extent, the spatial distribution of infiltrationexcess and saturation-excess runoff is regular. For example, Burns et al. found that the runoff from the outcrop, which occupied about one-third of the catchment area, was most likely as infiltration-excess runoff and contributed more than half of the peak streamflow [21]. Buda et al. found that, in upslope positions without a fragipan, runoff was generated primarily via the infiltration-excess mechanism (96\% of events) [22]. As a preliminary study, based on the concept of dominant hydrological processes, we tried to divide the watershed into saturation-excess dominated (SED) areas and infiltration-excess dominated (IED) areas for event simulation and then validate whether this division can increase model realism and improve simulation accuracy.

Based on the landscape factors, a parallel-featured spatial combination modeling framework is proposed for event hydrological simulation in this paper. In this framework, the runoff curve number (simply called $\mathrm{CN}$ ) [23] is employed to delineate the IED areas, and the topographic index (simply called TI) [24] is employed to delineate the SED areas. The spatial combination model (SCM) is built accordingly, in which the saturation-excess module and infiltration-excess module are used in SED and IED areas, respectively. The total runoff is the sum of infiltration-excess and saturation-excess runoff.

\section{Study Area and Data}

2.1. Study Area. Dongwan watershed is located in the source area of Yihe River Basin in Henan Province, China (Figure 1). The annual precipitation in Yihe River Basin ranges from $500 \mathrm{~mm}$ to $1100 \mathrm{~mm}$ and tends to increase as elevation increases. The mountainous areas are rainy and the valleys as well as the adjacent hilly areas are relatively dry. The distribution of precipitation during the year is uneven. The precipitation from July to September accounts for more than $50 \%$ of a whole year. The maximum annual precipitation is about 2 times larger than the least.

Dongwan watershed is located between longitude $111^{\circ} \sim$ $112^{\circ} \mathrm{E}$ and latitude $33.5^{\circ} \sim 34.5^{\circ} \mathrm{N}$, covering a drainage area of $2856 \mathrm{~km}^{2}$, belonging to a continental monsoon climate. The west of the watershed is high and the east is relatively low. The upstream area is mainly covered by forest. The storm is the major cause of the watershed flood which is characterized by sharp hydrograph, high peak, and short duration and is a great threat to the downstream area.

Dongwan watershed is a semihumid watershed. According to the magnitude of annual precipitation, the shape of flood hydrographs, the extent of vegetation coverage, and other factors, it is apparent that both saturation-excess and infiltration-excess mechanisms play an important role in the processes of direct runoff generation and routing.

2.2. Data. The digital elevation data are obtained from the second version of ASTER GDEM data released by NASA, at a $30 \mathrm{~m}$ spatial resolution. The soil data is obtained from the $1: 1,000,000$ scale vector-based soil map data provided by the Institute of Soil Science, Chinese Academy of Science, which contains the information of sand content (particle diameter $>0.05 \mathrm{~mm}$, according to US Soil Taxonomy), silt content (diameter between $0.05 \mathrm{~mm}$ and $0.002 \mathrm{~mm}$ ), clay content (diameter $<0.002 \mathrm{~mm}$ ), saturated hydraulic conductivity, and so forth, for $0-20 \mathrm{~cm}$ depth and $20-100 \mathrm{~cm}$ depth, respectively. The vegetation data are obtained from the landsat 8 imagery data provided by USGS, path/row numbers 125/36. 


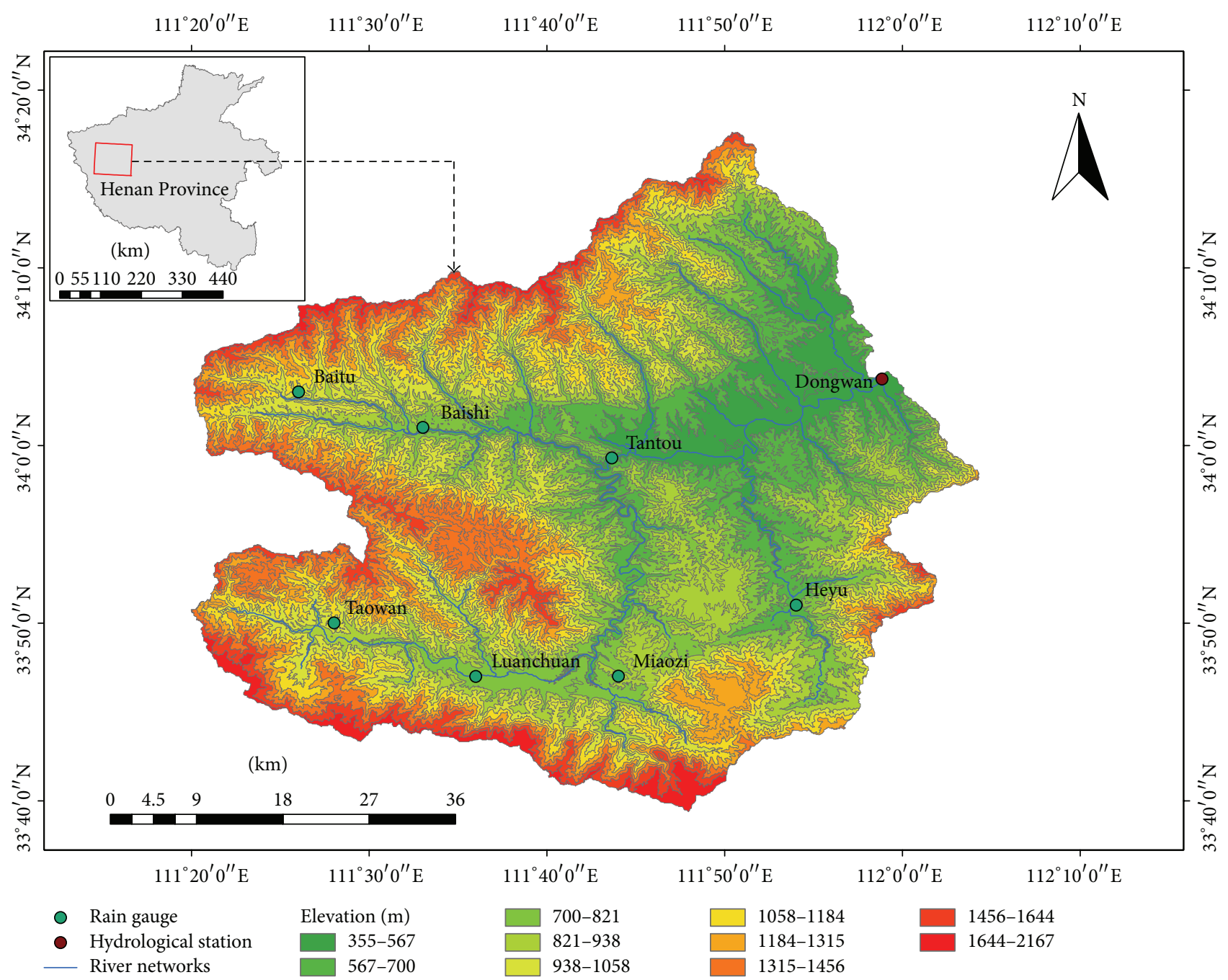

FIGURE 1: Location, topography, and river networks of Dongwan watershed.

Hydrological data include precipitation, streamflow, and pan-evaporation data, provided by the Yellow River Conservancy Commission (YRCC). There are 8 rain-gauge stations in Dongwan watershed and one hydrological station at the outlet of the watershed. Daily hydrological data are available from 1960 to 2011, except for 1969. Subdaily data are only available during flood events in the years of 1961-1968, 1973, $1975,1977,1981-1985,1994-1996,1998$, and 2000-2011. Due to the effects of human activities, the flood characteristics in the post-1980 period are significantly different from those in the pre-1980 period.

The subdaily data were interpolated into hourly data. Only the subdaily data after 1994 were precise and complete enough. The subdaily data in the pre-1994 period were confusing and difficult to collect, especially in the pre-1980 period. As a result, the pre-1980 flood data were not used for calibration or validation. Flood events in the period of 1994 to 2001 were selected for calibration and those in the period of 1981 to 1985 were selected for validation.

Flood events in the calibration period were selected using the annual maximum method; thus, there were 16 flood events except 1997 and 1999 as no flood records in the two years. In the validation period, in order to choose more flood events, 7 flood events were selected using the method of Peaks over Threshold.

\section{Modeling Approach}

3.1. Saturation-Excess Model. Xinanjiang (XAJ) model, the most popular conceptual rainfall-runoff model in China, is a powerful tool not only for flood simulation and operational forecasting but also for hydrology research such as flood forecasts in ungauged basins [25] and impacts of rain gauge densities on runoff simulation [26]. The main merit of XAJ model is that it can account for the uneven spatial distribution of soil moisture storage capacity represented by a parabolic curve.

The tension water storage capacity at a point $W^{\prime}$, varying from zero to the watershed maximum value $W_{M M}$, is described by a nonlinear functional relationship (Figure 2),

$$
\frac{f}{F}=1-\left(1-\frac{W^{\prime}}{W_{M M}}\right)^{b},
$$




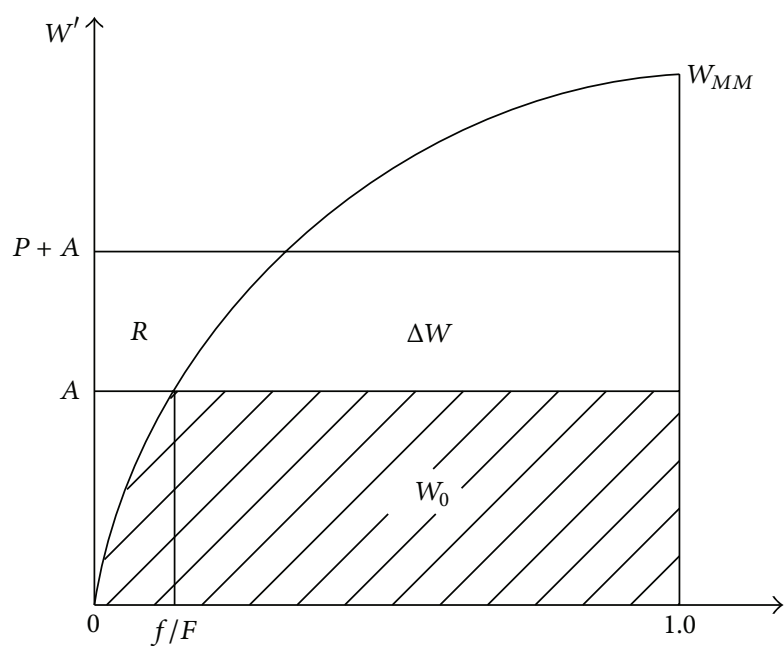

FIGURE 2: The spatial distribution of tension water capacity represented in XAJ model. $W^{\prime}$ is the tension water capacity at a certain point, $W_{M M}$ is the maximum value of $W^{\prime}$ within a watershed, $f / F$ is the portion of the watershed area having tension water capacity smaller than $W^{\prime}, A$ is the value of the vertical axis corresponding to $f / F, P$ is the precipitation, $R$ is the runoff, $W_{0}$ is the antecedent soil moisture content prior to an event, and $\Delta W$ is the change in the soil moisture content.

where $f$ is the partial pervious area of the watershed whose tension water storage capacity is less than or equal to $W^{\prime}, F$ is the total pervious area of the watershed, and $b$ is the shape parameter of the parabolic curve.

According to Figure 2, the initial soil moisture content $W_{0}$ can be acquired by integral calculation:

$$
\begin{aligned}
W_{0} & =\int_{0}^{A}\left(1-\frac{f}{F}\right) d W^{\prime} \\
& =\frac{W_{M M}}{b+1}\left[1-\left(1-\frac{A}{W_{M M}}\right)^{b+1}\right] .
\end{aligned}
$$

If $A=W_{M M}$, then $W_{0}=W_{M}$ and $W_{M}=W_{M M} /(1+b)$.

According to (2), the following equation can be expressed as follows:

$$
A=W_{M M}\left[1-\left(1-\frac{W_{0}}{W_{M}}\right)^{1 /(1+b)}\right] .
$$

In XAJ model, runoff occurs only at the points where the tension water capacities are filled with precipitation. Hence, the formula of total runoff can be derived:

$$
\begin{aligned}
R & =\int_{A}^{P_{E}+A} \frac{f}{F} d W^{\prime} \\
& =\int_{A}^{P_{E}+A}\left[1-\left(1-\frac{W^{\prime}}{W_{M M}}\right)^{b}\right] d W^{\prime} .
\end{aligned}
$$

If $P_{E}+A<W_{M M}$, then the runoff formula is

$$
R=P_{E}-\left(W_{M}-W_{0}\right)+W_{M}\left(1-\frac{P_{E}+A}{W_{M M}}\right)^{1+b}
$$

If $P_{E}+A \geq W_{M M}$, then the runoff formula is

$$
R=P_{E}-\left(W_{M}-W_{0}\right) \text {. }
$$

The schematic diagram and more details about XAJ model can be found in $[27,28]$.

\subsection{Infiltration-Excess Model}

3.2.1. Infiltration Curve. The runoff generation module of Hebei model [29], which is locally used in the Hebei Province of China for flood forecasting, is adopted to build the infiltration-excess model using the modified Horton equation,

$$
f=f_{c}+f_{0} e^{-u m} .
$$

In the above equation $f$ is the infiltration capacity, $f_{c}$ is the steady-state infiltration capacity, $f_{0}$ is the initial infiltration capacity, $u$ is an infiltration coefficient, and $m$ is the surface soil moisture content calculated by the following equation:

$$
m=F_{s}+k_{i m} P_{a},
$$

where $k_{i m}$ is a coefficient representing the ratio of surface soil thickness to the vadose zone thickness, ranging from 0 to $1, P_{a}$ is the antecedent soil moisture content, and $F_{s}$ is the cumulative infiltration amount during a flood event.

3.2.2. Spatial Distribution Curve of Infiltration Capacity. The spatial infiltration capacity distribution curve is analogous to the spatial storage capacity distribution curve applied in XAJ model, which indicates the spatial variation in point infiltration capacity over the watershed. Similar upscaled expression for areal average infiltration capacity can be seen in [30]. Surface runoff is generated at the point where the precipitation rate exceeds the infiltration capacity (Figure 3):

$$
\frac{F_{A}(t)}{F}=1-\left(1-\frac{f^{\prime}(t)}{f_{m m}}\right)^{n} .
$$

In formula (9) $F_{A}(t)$ is the partial area of the watershed whose infiltration capacity is less than or equal to $f^{\prime}(t)$ which is equivalent to the rainfall intensity $i(t)$ in the time interval $t$, $f_{m m}$ is the maximum point infiltration capacity, $F$ is the total area of the watershed, and $n$ is the shape parameter of the spatial distribution curve.

The initial areal average infiltration capacity $\overline{f_{0}(t)}$ corresponding to the rainfall intensity $i(t)$ can be calculated as

$$
\begin{aligned}
& \overline{f_{0}(t)}=i(t)-\frac{i(t)^{1+n}}{(1+n) f_{m m}^{n}}, \quad i(t)<f_{m m}, \\
& \overline{f_{0}(t)}=f_{m m}-\frac{f_{m m}}{1+n}, \quad i(t) \geq f_{m m} .
\end{aligned}
$$

3.2.3. Runoff Generation and Routing. Integrating (7) with (11), the surface infiltration capacity in the time interval $t$ can be calculated as

$$
f(t)=\left(i(t)-\frac{i(t)^{1+n}}{(1+n) f_{m m}^{n}}\right) e^{-u m(t)}+f_{c} .
$$




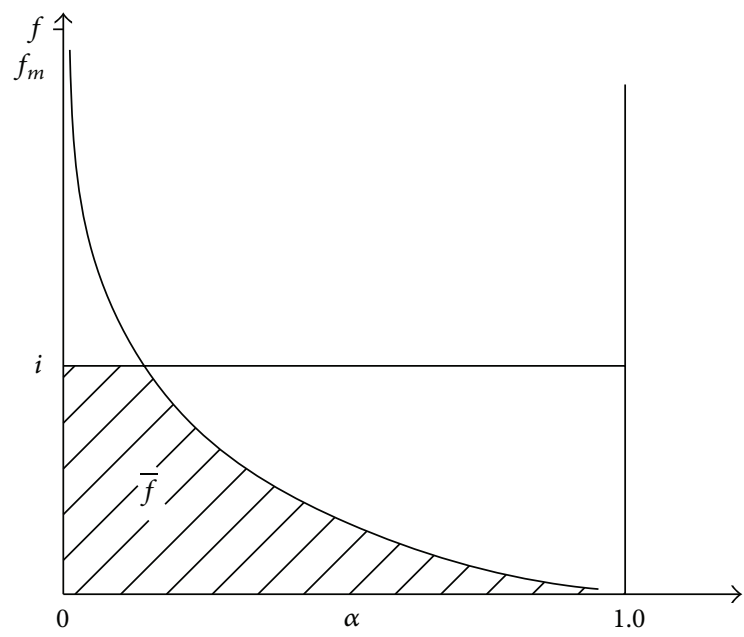

FIGURE 3: The spatial distribution of infiltration capacity represented in infiltration-excess model. $f$ is the infiltration capacity at a certain point, $f_{m m}$ is the maximum value of $f$ within a watershed, $\alpha$ is the portion of the watershed area having the infiltration capacity smaller than $f, i$ is the rainfall intensity, and $\bar{f}$ is the average infiltration rate corresponding to $i$.

The surface runoff in the time interval $t$ is calculated as

$$
R_{s}(t)=P(t)-F(t),
$$

where $P(t)$ is the precipitation amount in the time interval $t$ and $F(t)$ is the infiltration amount in the time interval $t$.

The calculation of subsurface runoff generation in infiltration-excess model is similar to the runoff generation calculation in XAJ model, using (5) and (6).

The method of runoff routing calculation in infiltrationexcess model is the same as that in XAJ model.

\subsection{Spatial Combination Modeling Framework}

3.3.1. Subwatershed Divisions. Digital elevation data are mainly used to outline the watershed boundary, extract the river network, and divide the watershed into subwatersheds.

Runoff mechanisms are determined by the combined effects of landscape factors and meteorological factors. Meteorological factors are closely related to terrain factors [31, 32]; for example, elevation and aspect factors have a strong impact on rainfall factors.

Landscape factors include terrain factors, vegetation factors, soil factors, and geological factors. The first three factors have a strong control on the surface runoff generation. Although the spatial distribution of landscape factors in a watershed is extremely complex, the distributed modeling needs to consider the spatial heterogeneity of these factors. When the entire watershed is divided into several or more subwatersheds, factors in subwatersheds are relatively simple and single; therefore, it is easier to judge runoff mechanisms in subwatersheds.

In this study, Dongwan watershed is divided into 52 subwatersheds using the ARC Hydro data model, which is developed and maintained by ESRI. The largest subwatershed covers an area of $134 \mathrm{~km}^{2}$, while the smallest subwatershed covers only $10 \mathrm{~km}^{2}$. The rainfall data for each subwatershed is obtained from the rain-gauge station which is nearest to the subwatershed centroid.

3.3.2. Topographic Index Calculation. Beven and Kirkby first proposed the concept of topographic index in 1979 and defined it as $\ln (\alpha / \tan \beta)$, where $\alpha$ is the local upslope area draining through a certain point per unit contour length and $\tan \beta$ is the local slope [24]. Beven thought that the water flow was mainly controlled by terrain; thus, topographic index can reflect the long-term soil moisture condition of every point in a watershed. Generally, topographic index is larger in valleys, riversides, and so forth, where the soil is moist and is liable to be saturated during storms. On the contrary, it is relatively smaller in peaks, ridges, and so forth, where the soil is relatively dry and is difficult to be saturated during storms. In hydrological modeling, topographic index is often used as a physically meaningful indicator, which can be used to quantitatively evaluate the effect of terrain factors on saturation-excess runoff generation and estimate the specific locations of saturation-excess overland flow.

In this study, topographic index is calculated by the Tool Chain function in SAGA GIS of version 2.1.4, using the default multiple flow direction algorithm. SAGA GIS is a free and open source GIS software which can be downloaded from http://sourceforge.net/projects/saga-gis/. Then the areal average topographic index for each subwatershed can be calculated by the Zonal tool in ArcGIS 10.1 (Figure 4).

3.3.3. CNEstimation. Before estimating the $\mathrm{CN}$ value, remote sensing data and soil data should be processed first.

In order to take into account the effect of vegetation on runoff generation, land use information was extracted from Landsat 8 images and was classified into five classes: arable land, forest, building land, water area, and unused land (bare rock and bare soil). Forest area accounts for the largest percent of total watershed area, reaching $82.16 \%$, followed by unused land area, constituting $10.42 \%$. The area of the remaining land use types only accounts for $7.42 \%$.

Runoff generation processes are also affected by soil types. The US Natural Resources Conservation Service has ever proposed a soil classification method from the perspective of rainfall-runoff relationship. According to the hydrological properties and runoff potential, soils can be classified into four groups, A, B, C, and D, as shown in Table 1 and Figure 5.

SCS-CN model assumes that "the ratio of actual runoff to the maximum potential runoff is equal to the ratio of the actual infiltration amount to the maximum possible infiltration amount," which can be employed to calculate the direct runoff generated during a storm. The model is popular in the world as it is simple and easy to use [23].

$\mathrm{CN}$ is the only parameter of the model, which is a dimensionless number and can represent the degree of infiltration loss. It can be determined by soil type, land use type, surface morphology, and antecedent soil moisture content without calibration. Since surface morphology can be represented by topographic index, $\mathrm{CN}$ is only related to soil type and land use type in this study, determined using Table 2. 
TABLE 1: Hydrological soil groups.

\begin{tabular}{lcll}
\hline $\begin{array}{l}\text { Hydrologic } \\
\text { soil group }\end{array}$ & $\begin{array}{l}\text { Saturated hydraulic } \\
\text { conductivity } \mathrm{mm} / \mathrm{h}\end{array}$ & Runoff generation characteristics & Soil types \\
\hline A & $>110$ & $\begin{array}{l}\text { Soils have low runoff potential and high infiltration } \\
\text { rates even when thoroughly wetted } \\
\text { Soils have moderate infiltration rates when thoroughly } \\
\text { wetted }\end{array}$ & Mainly sand, loamy sand, and sandy loam \\
B & $14 \sim 110$ & $\begin{array}{l}\text { Soils have low infiltration rates when thoroughly wetted sand and loam } \\
\text { Soils have high runoff potential and very low } \\
\text { infiltration rates even when thoroughly wetted }\end{array}$ & $\begin{array}{l}\text { Mainly sandy clay loam } \\
\text { Mainly clay loam, silty clay loam, sandy } \\
\text { clay, silty clay, and clay }\end{array}$ \\
\hline
\end{tabular}
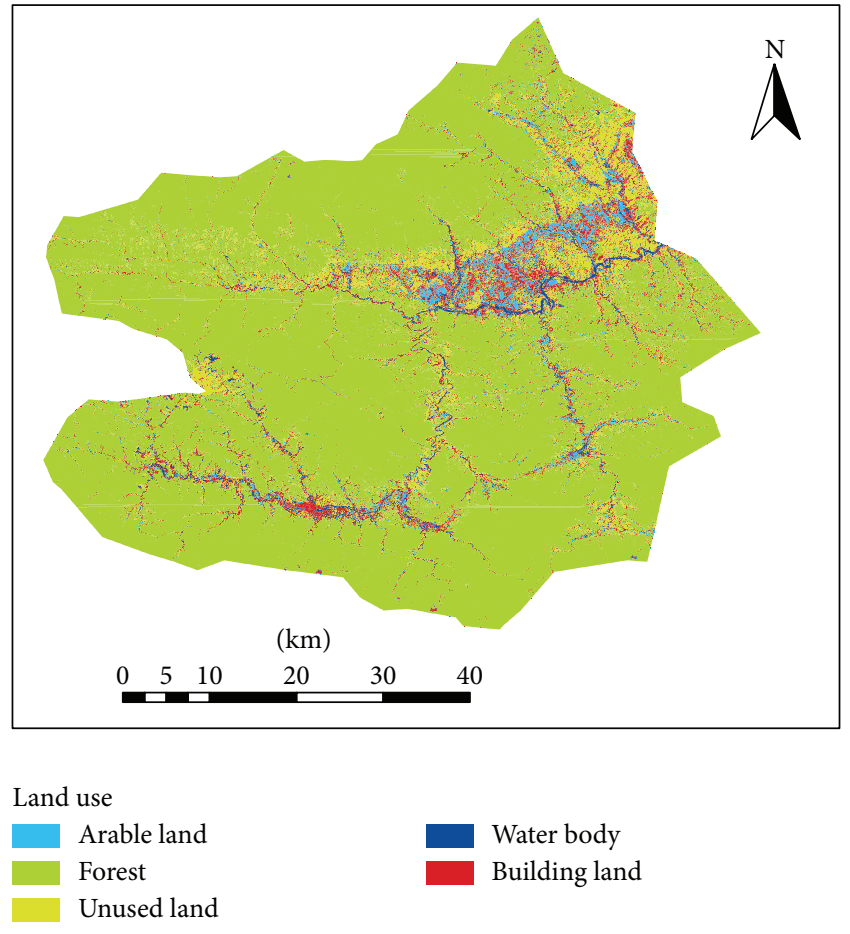

FIGURE 4: Land use map for Dongwan watershed.

TABLE 2: CN values.

\begin{tabular}{lcccc}
\hline Land use type & $\mathrm{A}$ & $\mathrm{B}$ & $\mathrm{C}$ & $\mathrm{D}$ \\
\hline Arable land & 67 & 78 & 85 & 89 \\
Forest & 25 & 55 & 70 & 77 \\
Water body & 100 & 100 & 100 & 100 \\
Building land & 51 & 68 & 79 & 84 \\
Unused land & 72 & 82 & 88 & 90 \\
\hline
\end{tabular}

Now CN is a static index, reflecting the infiltration capacity of land surface under normal humidity conditions and representing the potential of infiltration-excess runoff. A large $\mathrm{CN}$ value shows a small infiltration capacity of land surface, where infiltration-excess runoff is likely to occur. Similarly, a small CN value indicates a large infiltration capacity, where infiltration-excess runoff is unlikely to occur.

The areal $\mathrm{CN}$ value for each subwatershed can be obtained by the Zonal tool in ArcGIS 10.1.

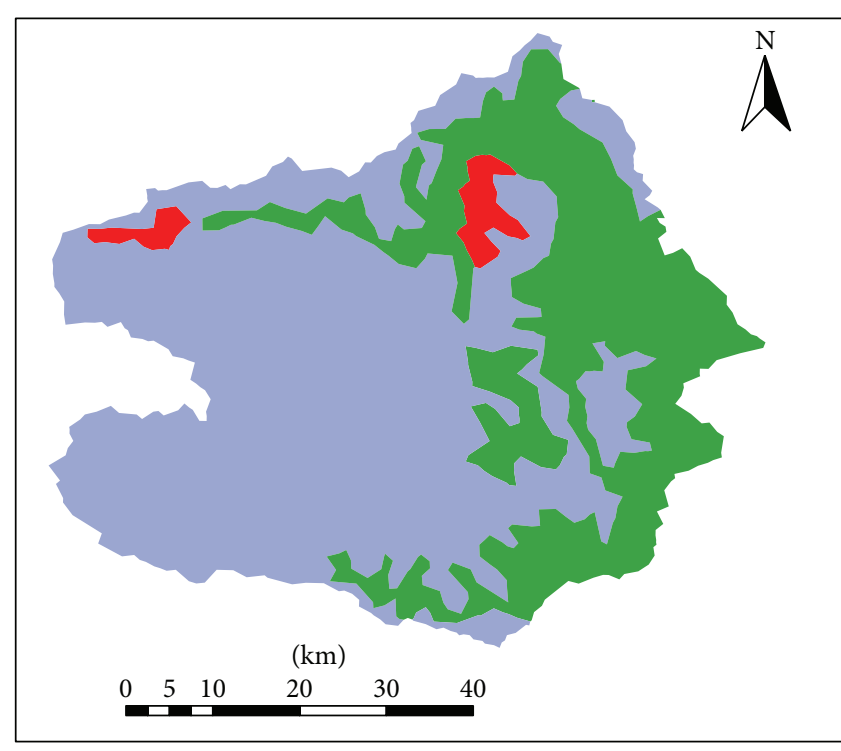

Soil group
A
B
D

FIgURE 5: Hydrological soil group map for Dongwan watershed.

3.3.4. Model Construction. Dongwan watershed is divided into SED subwatersheds and IED subwatersheds based on the concept of dominant hydrological processes [33]. The actual runoff processes are extremely complex, and the saturationexcess runoff and infiltration-excess runoff in a watershed are spatially and temporally dynamic. Currently, hydrologists are not able to make a complete simulation of such complex runoff processes and only able to capture the essential runoff features, that is, dominant hydrological processes. For example, in a SED subwatershed which is characterized by lush vegetation, porous soil, and flat terrain, the saturation-excess runoff is likely to occur but not necessarily to occur. Although this subwatershed may be dominated by infiltration-excess runoff during few flood events, it is dominated by saturationexcess runoff during most flood events, especially medium and large flood events.

Compared with complete simulation of runoff processes, simulation of dominant hydrological processes is more important and reliable, because it needs less data and computational power and can avoid some difficult problems such as 
overparameterization which are currently hard to deal with. Two methods are used in this paper to divide the study watershed into SED subwatersheds and IED subwatersheds: one is $\mathrm{CN}$ division method and the other is CN-TI division method. $\mathrm{CN}$ division method sorts the subwatersheds according to their areal $\mathrm{CN}$ values using the Natural Break function in ArcGIS 10.1. Subwatersheds with smaller areal $\mathrm{CN}$ value are considered as SED subwatersheds, and the other are IED subwatersheds. The model based on this method is named SCM I. CN-TI division method is the improved CN division method. Based on the result of the $\mathrm{CN}$ division method, the IED subwatersheds with larger topographic index are changed as SED subwatersheds. The constructed model is named SCM II accordingly.

XAJ model is employed in SED subwatersheds for runoff calculation and infiltration-excess model is implemented in IED subwatersheds.

The linear reservoir method is used to simulate runoff concentration in the river network of each subwatershed and segmented Muskingum formula is used to simulate runoff routing from the subwatershed outlet to the watershed outlet, which is the same as that used in XAJ model.

3.4. Model Calibration and Evaluation. When using the single runoff model (XAJ model and infiltration-excess model), Dongwan watershed was divided into 8 subwatersheds through Thiessen polygon method. When using SCM I and SCM II, the watershed was divided into 52 subwatersheds as mentioned above. To lighten the computational burden and reduce the parameter uncertainty, only sensitive parameters were automatically calibrated by the SCE-UA global optimization algorithm $[34,35]$. Because flood runoff mainly includes surface runoff and rapid interflow, the model parameters associated with these runoff components can be identified as sensitive parameters. In saturation-excess module, the identified sensitive parameters are $S_{M}$ and $C_{I}$; and in infiltration-excess module, they are $k_{i m}, f_{c}, u$, and $f_{m m}$. In addition, $C_{S}$ is also very sensitive, which represent the effect of the river network on runoff processes.

Daily version of XAJ model was used to initialize the event model, calculating the soil moisture condition prior to each flood event. The period of 1994 to 2001 was selected as calibration period and the period of 1981 to 1985 was selected as validation period. The application of XAJ model can be seen in detail in $[27,28]$.

The performance of the model is evaluated using the following criteria on a relative basis.

The relative error of runoff depth:

$$
\Delta R_{T}(\%)=\frac{R_{\mathrm{CD}}-R_{\mathrm{OD}}}{R_{\mathrm{OD}}} \times 100 \% .
$$

The relative error of peak flow:

$$
\Delta Q_{p}(\%)=\frac{Q_{\mathrm{CP}}-Q_{\mathrm{OP}}}{Q_{\mathrm{OP}}} \times 100 \%,
$$

where $R_{\mathrm{CD}}$ and $Q_{\mathrm{CP}}$ refer to the simulated runoff depth and peak flow, $R_{\mathrm{OD}}$ and $Q_{\mathrm{OP}}$ refer to the observed runoff depth and peak flow.
Referring to the national criteria for flood forecasting in China, (14) is transformed into a binary function [36, 37],

$$
Q_{u v}= \begin{cases}1, & \Delta R_{T} \leq 20 \% \\ 0, & \Delta R_{T}>20 \%\end{cases}
$$

where $Q_{u v}$ indicates whether the runoff depth simulation is qualified. 1 means qualified and 0 means unqualified.

Likewise,

$$
Q_{u p}= \begin{cases}1, & \Delta Q_{p} \leq 20 \%, \\ 0, & \Delta Q_{p}>20 \%\end{cases}
$$

where $Q_{u p}$ indicates whether the peak flow simulation is qualified.

Thus, the qualified rates of peak flow simulation $R_{p}$ and runoff depth simulation $R_{v}$ can be calculated as follows:

$$
\begin{aligned}
& R_{p}=\sum_{i=1}^{n} \frac{Q_{u p, i}}{n}, \\
& R_{v}=\sum_{i=1}^{n} \frac{Q_{u v, i}}{n},
\end{aligned}
$$

where $n$ is the number of simulated runoff events. In China, the model can be used for operational flood forecasting only when its qualified rate exceeds $70 \%$.

Different objective functions are in favor of different hydrographic components. For hydrological event simulation, the objective function should be in favor of high flows. If the objective function was selected appropriately, the calibrated parameter values are more realistic [38]. In this study, the objective function involves simulation of peak flow and runoff depth, aggregating (18) and (19):

$$
\mathrm{CR}=\frac{1}{\left(\sum_{i=1}^{n} Q_{u v, i}+\sum_{i=1}^{n} Q_{u p, i}+1\right)}
$$

\section{Results}

4.1. Results of Subwatershed Division. Figure 6(a) shows the result of the $\mathrm{CN}$ division method. The IED subwatershed area accounts for about $68 \%$ of the total watershed area, most of which are located in the upstream and located on the north of the main river channel in the downstream. In the upstream there are mainly group B soils with medium infiltration capacity; therefore, infiltration-excess runoff tends to occur under high rainfall intensity. In the downstream there are mainly group A soils with high infiltration capacity; however, the north side of the main river channel is predominantly made up of bare soils with low vegetation coverage and consequently classified as IED subwatersheds.

Figure 6(b) shows the result of CN-TI division method, where the IED subwatershed area occupies about $50 \%$ of the total area. After considering the terrain factors, the number of IED subwatersheds in the downstream is significantly reduced, only one left. In other words, the IED subwatersheds 


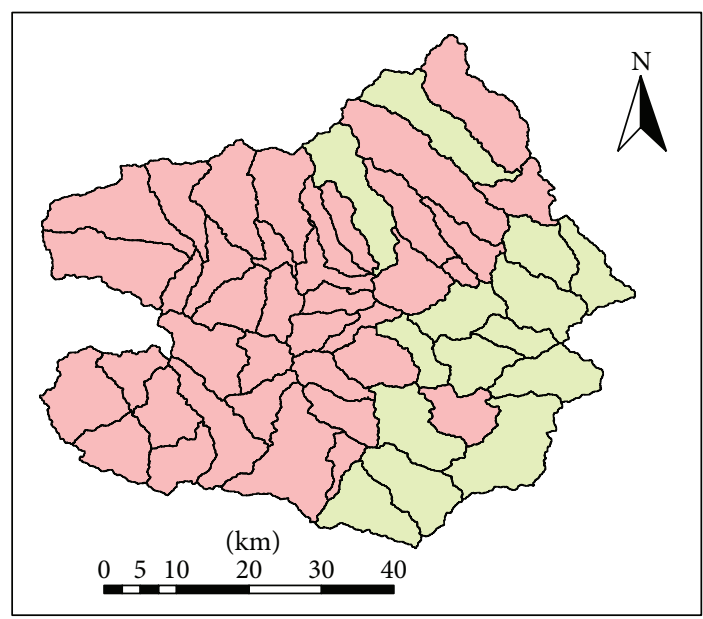

SED subwatersheds IED subwatersheds

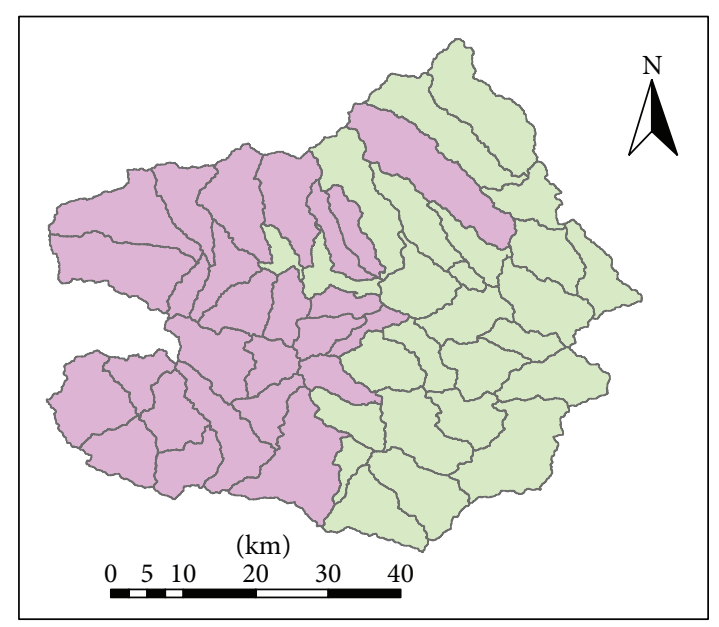

SED subwatersheds IED subwatersheds

(a)

(b)

FIGURE 6: Division results of the saturation-excess dominated (SED) subwatersheds and infiltration-excess dominated (IED) subwatersheds for Dongwan watershed. (a) CN division method and (b) CN-TI division method.

are concentrated in the upstream. The result suggests that, without the disturbing effects of human activities, terrain factors are somewhat correlated to vegetation and soil factors; for example, soil infiltration capacity and vegetation cover on steep slopes are usually lower than those on gentle slopes.

4.2. Results of Parameter Calibration. Table 3 shows the optimized parameters of XAJ model and infiltration-excess model. For XAJ model, the parameter $S_{M}$ which is highly associated with runoff separation has a value of only $26 \mathrm{~mm}$. The smaller the $S_{M}$ value, the larger the proportion of surface runoff. In XAJ model, surface runoff refers to the saturationexcess overland flow. It is obvious that saturated surface runoff is not likely to account for a large proportion of total runoff in such a watershed. In fact, infiltration-excess runoff is treated as saturation-excess runoff in XAJ model for Dongwan watershed.

For infiltration-excess model, the parameter value of $k_{i m}$ is only 0.4 , less than 0.5 . The closer to $1 k_{i m}$ is, the greater the effect of antecedent soil moisture content on direct runoff generation is, and the closer to the saturation-excess mechanism is. On the contrary, the closer to $0 k_{i m}$ is, the greater the effect of current rainfall infiltration is, and the closer to the infiltration-excess mechanism is. The value of the $k_{i m}$ indicates that the effect of infiltration-excess mechanism is quite large in Dongwan watershed, even larger than that of saturation-excess mechanism.

Table 4 shows the optimization result of two SCM models. Contrasted with XAJ model, the $S_{M}$ value increases from $26 \mathrm{~mm}$ to $34 \sim 35 \mathrm{~mm}$, which means that the proportion of saturated surface runoff is reduced. In SCM model the overland flow is divided into saturation-excess overland flow in SED areas and infiltration-excess overland flow in IED areas. The reduced saturation-excess overland flow is replaced by the increased infiltration-excess overland flow, which is more consistent with the actual condition in Dongwan watershed.

Changes in parameter values associated with (7) and (8) are more complicated. $k_{i m}$ is insensitive with little change. $f_{c}$ and $u$ are sensitive parameters, both of which can affect infiltration capacity according to (7). Hence, the effect of equifinality cannot be ruled out. In general, compared to infiltration-excess model and SCM I, the areal average infiltration capacity in SCM II is relatively lower and consequently the amount of infiltration-excess runoff is relatively higher, which is more consistent with actual conditions as discussed in Section 5. In SCM model the entire watershed is divided into SED areas and IED areas and the overland flow is also divided into saturation-excess and infiltration-excess overland flow. Therefore, the representation of runoff generation mechanism in the semihumid watershed is clearer and more precise.

4.3. Results of Simulation and Validation. The model simulation results are shown in Table 5. For XAJ model, the qualified rates of runoff depth simulation and peak flow simulation are both $68.8 \%$; for infiltration-excess model, the qualified rate of runoff depth simulation is $68.8 \%$ and the qualified rate of peak flow simulation is $62.8 \%$, almost equal to XAJ model, which reflects the problem of model structure uncertainty; for SCM I, both are 75\%; and for SCM II, the qualified rate of runoff depth simulation is $75 \%$ and the qualified rate of peak flow simulation is $81.3 \%$, showing a large improvement of simulation accuracy.

Peak flow forecasting is a crucial factor for flood forecasting and warning in small and medium watersheds. There are only three unqualified peak flow forecasts by SCM II, which are the forecasts of 960802, 070729, and 090828 flood events 
TABLE 3: The optimized parameters of the single runoff models.

\begin{tabular}{|c|c|c|c|c|c|}
\hline \multicolumn{3}{|l|}{ XAJ model } & \multicolumn{3}{|c|}{ Infiltration-excess model } \\
\hline Parameter meaning & Notation & Value & Parameter meaning & Notation & Value \\
\hline $\begin{array}{l}\text { Ratio of potential evapotranspiration to } \\
\text { pan evaporation }\end{array}$ & K & 0.65 & $\begin{array}{l}\text { Ratio of potential evapotranspiration to } \\
\text { pan evaporation }\end{array}$ & K & 0.65 \\
\hline $\begin{array}{l}\text { Exponential parameter with a single } \\
\text { parabolic curve, which represents the } \\
\text { nonuniformity of the spatial distribution } \\
\text { of the soil moisture storage capacity over } \\
\text { the catchment }\end{array}$ & $b$ & 0.3 & $\begin{array}{l}\text { Exponential parameter with a single } \\
\text { parabolic curve, which represents the } \\
\text { nonuniformity of the spatial distribution } \\
\text { of the soil moisture storage capacity over } \\
\text { the watershed }\end{array}$ & $b$ & 0.3 \\
\hline $\begin{array}{l}\text { Coefficient of the deep layer that depends } \\
\text { on the proportion of the basin area } \\
\text { covered by vegetation with deep roots }\end{array}$ & C & 0.08 & $\begin{array}{l}\text { Coefficient of the deep layer that depends } \\
\text { on the proportion of the basin area } \\
\text { covered by vegetation with deep roots }\end{array}$ & C & 0.08 \\
\hline $\begin{array}{l}\text { Averaged soil moisture storage capacity } \\
(\mathrm{mm})\end{array}$ & $W_{M}$ & 180 & $\begin{array}{l}\text { Averaged soil moisture storage capacity } \\
(\mathrm{mm})\end{array}$ & $W_{M}$ & 180 \\
\hline $\begin{array}{l}\text { Averaged soil moisture storage capacity of } \\
\text { the upper layer }(\mathrm{mm})\end{array}$ & $W_{\mathrm{UM}}$ & 20 & $\begin{array}{l}\text { Averaged soil moisture storage capacity of } \\
\text { the upper layer }(\mathrm{mm})\end{array}$ & $W_{\mathrm{UM}}$ & 20 \\
\hline $\begin{array}{l}\text { Averaged soil moisture storage capacity of } \\
\text { the lower layer }(\mathrm{mm})\end{array}$ & $W_{\mathrm{LM}}$ & 70 & $\begin{array}{l}\text { Averaged soil moisture storage capacity of } \\
\text { the lower layer }(\mathrm{mm})\end{array}$ & $W_{\mathrm{LM}}$ & 90 \\
\hline $\begin{array}{l}\text { Percentage of impervious areas in the } \\
\text { watershed }\end{array}$ & $I_{M}$ & 0.01 & $\begin{array}{l}\text { A coefficient representing the ratio of } \\
\text { surface soil thickness to the vadose zone } \\
\text { thickness }\end{array}$ & $k_{i m}$ & 0.4 \\
\hline $\begin{array}{l}\text { Areal mean free water capacity of the } \\
\text { surface soil layer, which represents the } \\
\text { maximum possible deficit of free water } \\
\text { storage }\end{array}$ & $S_{M}$ & 26 & $\begin{array}{l}\text { Steady-state infiltration capacity } \\
\left(\mathrm{mm} \cdot \mathrm{h}^{-1}\right)\end{array}$ & $f_{c}$ & 1.5 \\
\hline $\begin{array}{l}\text { Exponent of the free water capacity curve } \\
\text { influencing the development of the } \\
\text { saturated area }\end{array}$ & $E_{X}$ & 1.2 & $\begin{array}{l}\text { Exponent of the spatial infiltration } \\
\text { capacity distribution curve }\end{array}$ & $E_{X}$ & 1.6 \\
\hline $\begin{array}{l}\text { Outflow coefficients of the free water } \\
\text { storage to groundwater relationships }\end{array}$ & $K_{G}$ & 0.35 & $\begin{array}{l}\text { Infiltration coefficient of the improved } \\
\text { Horton equation }\end{array}$ & $u$ & 0.006 \\
\hline $\begin{array}{l}\text { Outflow coefficients of the free water } \\
\text { storage to interflow relationships }\end{array}$ & $K_{I}$ & 0.35 & $\begin{array}{l}\text { Recession constants of the interflow and } \\
\text { groundwater storage }\end{array}$ & $C_{\mathrm{IG}}$ & 0.95 \\
\hline $\begin{array}{l}\text { Recession constants of the groundwater } \\
\text { storage }\end{array}$ & $C_{G}$ & 0.998 & $\begin{array}{l}\text { The maximum point infiltration capacity } \\
\text { in the watershed }\left(\mathrm{mm} \cdot \mathrm{h}^{-1}\right)\end{array}$ & $f_{m m}$ & 312 \\
\hline $\begin{array}{l}\text { Recession constants of the lower interflow } \\
\text { storage }\end{array}$ & $C_{I}$ & 0.954 & $\begin{array}{l}\text { Recession constants in the lag and route } \\
\text { method for routing through the channel } \\
\text { system within each subbasin }\end{array}$ & $C_{S}$ & 0.057 \\
\hline $\begin{array}{l}\text { Recession constants in the lag and route } \\
\text { method for routing through the channel } \\
\text { system within each subbasin }\end{array}$ & $C_{S}$ & 0.014 & Lag in time (h) & $L$ & 0 \\
\hline Lag in time $(\mathrm{h})$ & $L$ & 0 & & & \\
\hline
\end{tabular}

with the relative errors of the peak flows $41.2 \%, 93.8 \%$, and $125 \%$, respectively. Such large forecast errors indicate that the abnormal results are caused not only by the model structure but also by the resolution and quality of hydrological data; for example, rainfall data fail to capture the storm center. XAJ model, infiltration-excess model, and SCM I also cannot make qualified forecasts of the three flood events. Therefore, we compare the forecast results of the four models excluding the three flood events.

Table 6 shows the model results in the validation period. The qualified rates of peak flows for XAJ model, infiltrationexcess model, SCM I, and SCM II are 57.1\%, 42.8\%, 57.1\%, and $71.4 \%$, respectively. Complex models often have high accuracy in the calibration period, but low accuracy in the validation period, due to overparameterization and overfitting [39]. The structure of SCM is more complex than that of XAJ model and infiltration-excess model, but its accuracy in the validation period is not lower, which indicates that the model performance is stable.

\section{Analysis of Two Flood Examples}

In this section the 060926 and 080720 flood events are taken as examples to assess the performances of the four models. Their hydrographs are shown in Figure 7.

For the 060926 flood event, the simulated peak flow of $\mathrm{XAJ}$ model is significantly greater than the observed peak flow, while the relative errors of the peak flow of the other 
TABLE 4: The optimized parameters of the spatial combination models.

\begin{tabular}{|c|c|c|}
\hline Parameter meaning & SCM I & SCM II \\
\hline Ratio of potential evapotranspiration to pan evaporation $K$ & 0.65 & 0.65 \\
\hline $\begin{array}{l}\text { Exponential parameter with a single parabolic curve, which represents the nonuniformity of the spatial } \\
\text { distribution of the soil moisture storage capacity over the watershed } b\end{array}$ & 0.3 & 0.3 \\
\hline $\begin{array}{l}\text { Coefficient of the deep layer that depends on the proportion of the basin area covered by vegetation with deep } \\
\text { roots } C\end{array}$ & 0.08 & 0.08 \\
\hline Averaged soil moisture storage capacity $W_{M}(\mathrm{~mm})$ & 180 & 180 \\
\hline Averaged soil moisture storage capacity of the upper layer $W_{\mathrm{UM}}(\mathrm{mm})$ & 20 & 20 \\
\hline Averaged soil moisture storage capacity of the lower layer $W_{\mathrm{LM}}(\mathrm{mm})$ & 90 & 90 \\
\hline Percentage of impervious areas in the watershed $I_{M}$ & 0.01 & 0.01 \\
\hline $\begin{array}{l}\text { Areal mean free water capacity of the surface soil layer, which represents the maximum possible deficit of free } \\
\text { water storage } S_{M}(\mathrm{~mm})\end{array}$ & 35 & 34 \\
\hline Exponent of the free water capacity curve influencing the development of the saturated area $E_{X}$ & 1.2 & 1.2 \\
\hline Outflow coefficients of the free water storage to groundwater relationships $K_{G}$ & 0.35 & 0.35 \\
\hline Outflow coefficients of the free water storage to interflow relationships $K_{I}$ & 0.35 & 0.35 \\
\hline Recession constants of the groundwater storage $C_{G}$ & 0.998 & 0.998 \\
\hline Recession constants of the lower interflow storage $C_{I}$ & 0.768 & 0.902 \\
\hline $\begin{array}{l}\text { Recession constants in the lag and route method for routing through the channel system within each subbasin } \\
C_{S}\end{array}$ & 0.038 & 0.026 \\
\hline Lag in time $L(\mathrm{~h})$ & 0 & 0 \\
\hline Coefficient representing the ratio of surface soil thickness to the vadose zone thickness $k_{i m}$ & 0.4 & 0.4 \\
\hline Steady-state infiltration capacity $f_{c}\left(\mathrm{~mm} \cdot \mathrm{h}^{-1}\right)$ & 1 & 1.2 \\
\hline Infiltration coefficient of the improved Horton equation $u$ & 0.004 & 0.007 \\
\hline The maximum point infiltration capacity in the watershed $f_{m m}\left(\mathrm{~mm} \cdot \mathrm{h}^{-1}\right)$ & 249 & 211 \\
\hline Exponent of the spatial infiltration capacity distribution curve $E_{X}$ & 1.5 & 1.7 \\
\hline Recession constants of the interflow and groundwater storage $C_{\mathrm{IG}}$ & 0.949 & 0.958 \\
\hline
\end{tabular}

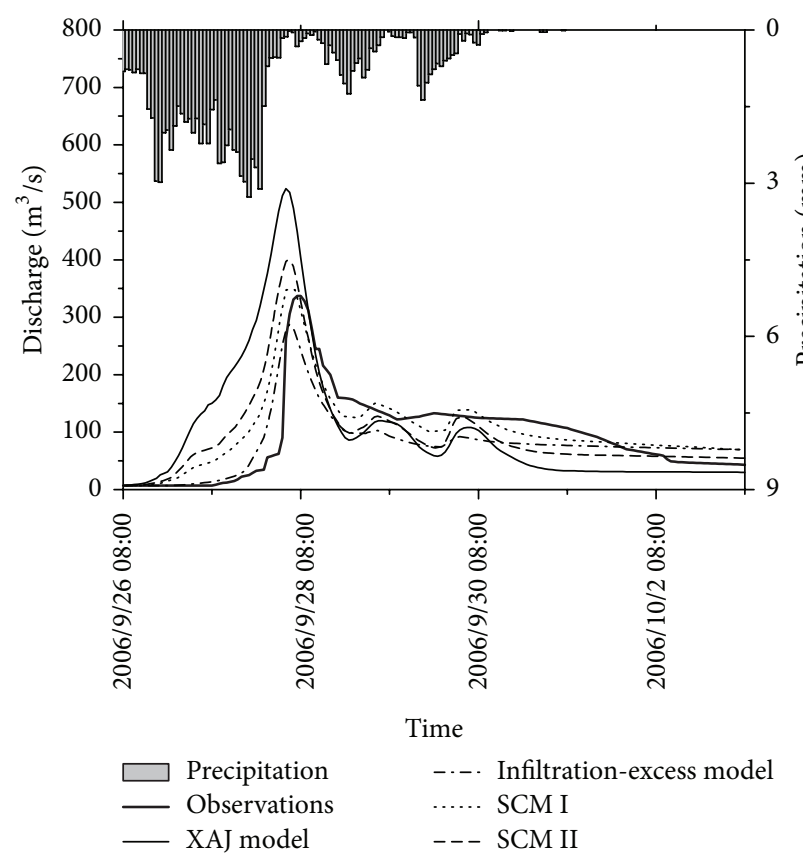

(a)

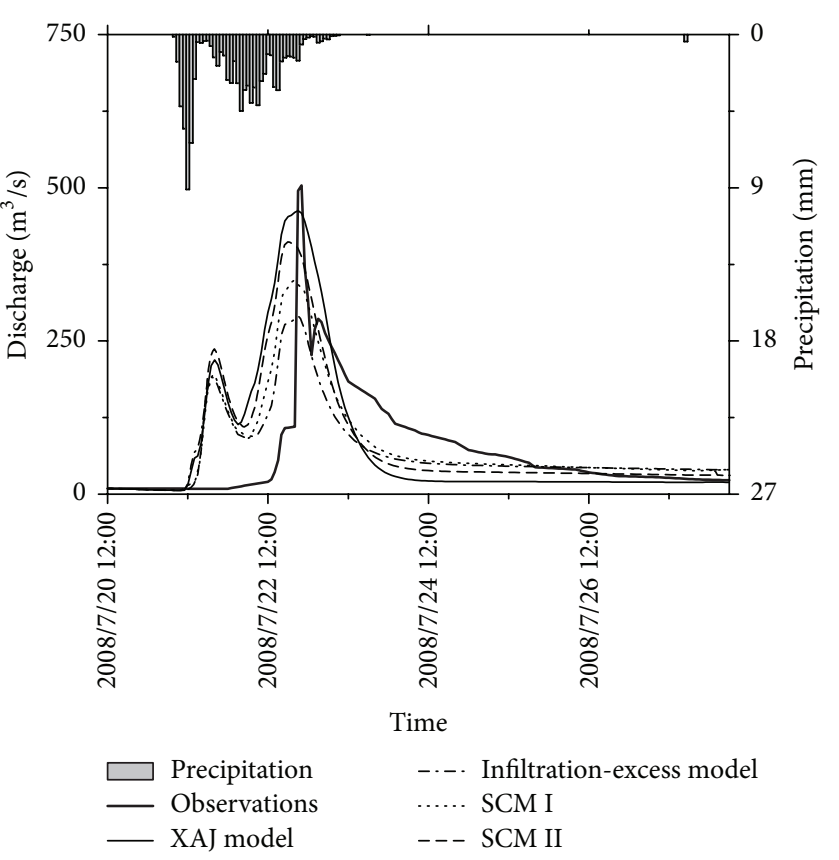

(b)

FIGURE 7: Observed and simulated runoff hydrographs for two events. (a) September 2006 and (b) July 2008. 


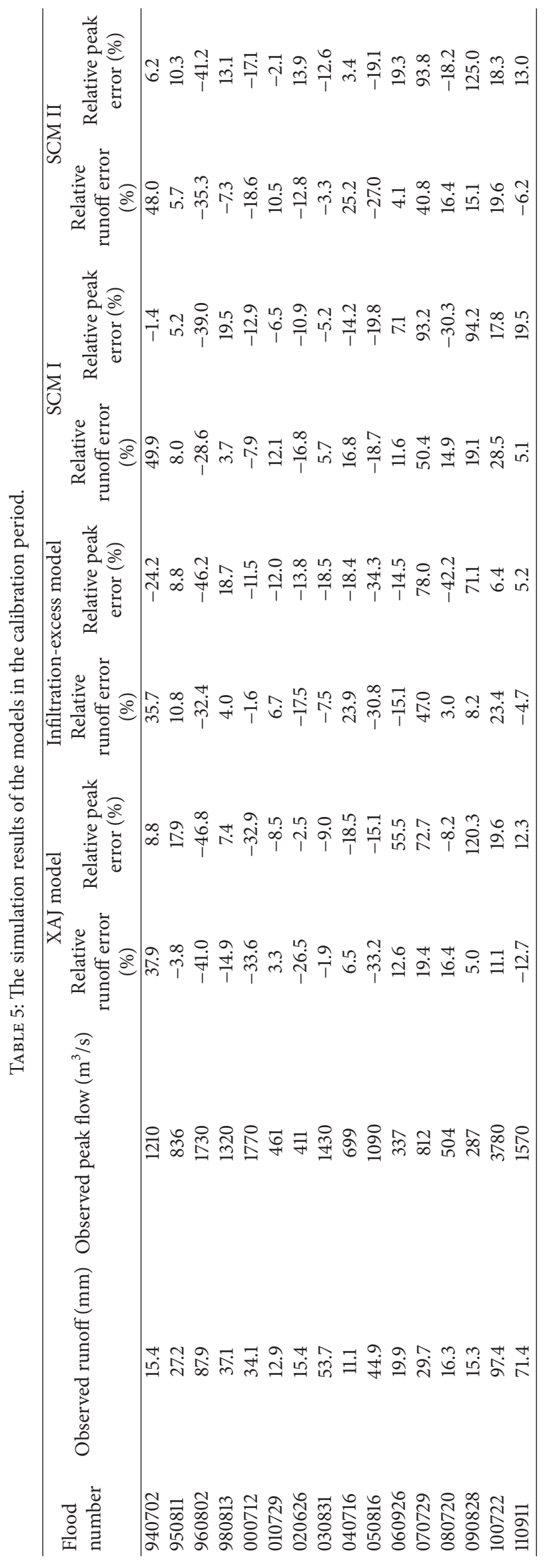




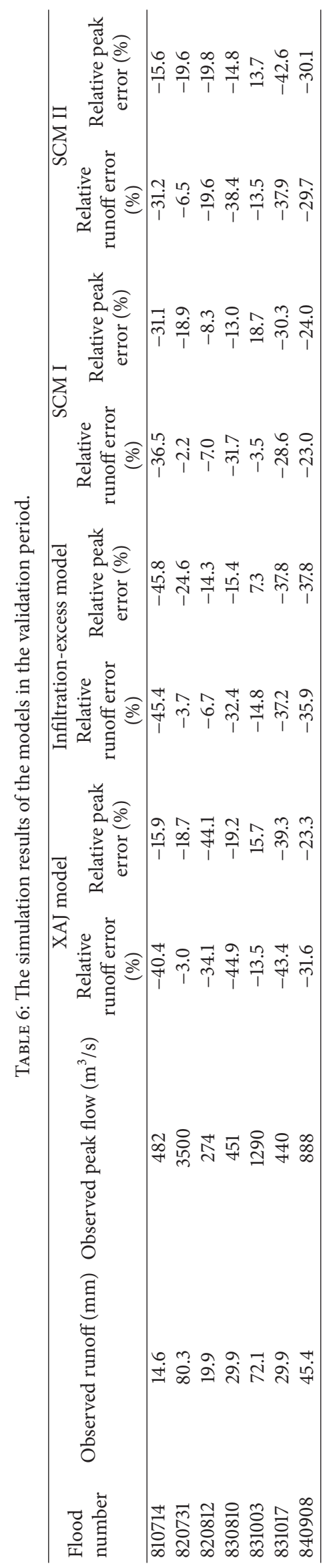


three models are in the $20 \%$ acceptable range. There was a heavy rain in the early September in 2006 and another heavy rain occurring around September 20. When the latter rain started on the evening of September 25, the soil was moist and the antecedent soil moisture content was about $130 \mathrm{~mm}$ $140 \mathrm{~mm}$ according to the daily water budget calculation. From the evening of September 25 to September 30, the rainfall continued and the total rainfall amount was large, which caused a large runoff according to the simulation result of XAJ model. As mentioned above, in XAJ model in semihumid watersheds, infiltration-excess runoff is replaced by saturation-excess runoff; therefore, when the antecedent soil moisture content is large, saturation-excess runoff is highly possible to occur, causing the simulated peak flow remarkably larger than the observed record. It also indicates that in mixed runoff watersheds the simulated peak flow of saturation-excess model is not always below the observed record and may be equal to or higher than it, but its underlying assumptions are not suitable for mixed runoff watersheds.

The infiltration-excess features of the 080720 flood event are more apparent compared to the 060926 flood event; for example, its hydrograph is much sharper. However, the simulation results are really interesting: XAJ model and SCM II can make a qualified peak flow forecast while the simulated peak flows of infiltration-excess model and SCM I, especially infiltration-excess model, are significantly lower than the actual record. Two rainfall peaks took place during the flood event. The first one happened between 12:00 and 13:00 on the July 21, 2008, with its storm center located among Tantou, Heyu, and Dongwan stations in the downstream, which were mainly SED areas. The second one occurred around 7:00 on the July 22 with the storm center located in Luanchuan in the upstream within IED areas. At the beginning of the rainfall, the soil was relatively dry with the antecedent soil moisture content around $110 \mathrm{~mm}$. Therefore, the rainwater of the first rainfall peak mainly infiltrated into the soil and the rainwater of the second rainfall peak mainly generated infiltration-excess runoff.

Although XAJ model can accurately reproduce the peak flow discharge of the 080720 flood event, its underlying assumptions are not applicable to Dongwan watershed. Despite the fact that the runoff mechanism of infiltrationexcess model is closer to the reality of Dongwan watershed, the optimized model parameters are far deviated from their physical meanings. Similarly, as the optimized $S_{M}$ parameter of XAJ model is too small, the areal average infiltration capacity calculated by the infiltration-excess model is too large, which in turn causes the proportion of infiltrationexcess runoff too small.

The simulated peak flows of the 080720 and 060926 flood events by infiltration-excess model are both smaller than the observed peak flow, indicating that even if the runoff mechanism represented by the model structure is close to the actual watershed condition, parameter identification is still a critical problem affecting simulation accuracies. Should the areal average infiltration capacity calculated by infiltrationexcess model be reduced to increase the infiltration-excess overland flow? The answer should be "no." There are also
SED flood events in Dongwan watershed; therefore, if the infiltration capacity is reduced, the simulated peak flows of SED flood events would be dramatically larger than the observed peak flows. That is to say, the calculated infiltration capacity by models may be greatly different from the actual infiltration capacity, just an "effective" variable.

SCM I also has the problem of the infiltration capacity being too large, but not obvious. This indicates that if the divisions of the SED and IED areas are precise enough, the parameter values and model variables would be closer to reality and the errors of model simulation will be reduced.

There is a peak in the simulated flood from all models around July 21, but there is no peak in the observed data. The observed data are basically flat in that period. This can be explained by the use of the parabolic distribution curve, which is described in Figures 2 and 3. The curve represents the spatial heterogeneity of hydrological variables; for example, soil water storage capacity is low in some points and high in some other points. With the use of these models, some points, such as the points with low storage capacity or low infiltration capacity, are prone to produce runoff. But in fact, no points produced runoff in the first rainfall peak. If the parabolic distribution is replaced by the uniform distribution, there may not be a peak in the simulated flood around July 21. In our future study, we will further investigate what conditions are applicable to the parabolic and uniform distribution, respectively.

\section{Conclusion}

This paper proposed the spatial combination modeling framework for event hydrological simulation. In this framework, the watershed is divided into saturation-excess dominated areas and infiltration-excess dominated areas by the joint use of curve number and topographic index, reflecting the phenomenon of saturation-excess runoff and infiltrationexcess runoff coexisting during a storm. The spatial combination model was also built according to the framework.

A semihumid watershed was taken as an example to test the framework. It can be found that

(1) the terrain factors are somewhat correlated to vegetation and soil factors. Therefore, the IED areas are mainly located in the upstream and the SED areas mainly in the downstream;

(2) the SCM outperforms the saturation-excess model and the infiltration-excess model both in the calibration and validation periods. The performance of the SCM is closely related to the division of SED and IED areas. A reasonable division can produce more realistic parameter values and better performances.

The results exhibit the importance of model realism for the event hydrological simulation. In the future study, the fuzzy approach and probabilistic approach will be used to seek for a more appropriate division of IED and SED areas within a watershed. In addition, this framework will be applied to a variety of semihumid watersheds based on the concept of "large-sample hydrology" [40]. 


\section{Conflict of Interests}

The authors declare that there is no conflict of interests regarding the publication of this paper.

\section{Acknowledgments}

This work was supported by the National Natural Science Foundation of China (Grant nos. 41130639, 51179045, and 41201028), the Nonprofit Industry Financial Program of MWR of China (201501022 and 201301068), the Meteorological Research Fund for Huaihe River Basin (HRM201404), and National Cooperative Innovation Center for Water Safety \& Hydro-Science.

\section{References}

[1] M. Hrachowitz, H. H. G. Savenije, G. Blöschl et al., "A decade of Predictions in Ungauged Basins (PUB) - a review," Hydrological Sciences Journal, vol. 58, no. 6, pp. 1198-1255, 2013.

[2] T. Euser, H. C. Winsemius, M. Hrachowitz, F. Fenicia, S. Uhlenbrook, and H. H. G. Savenije, "A framework to assess the realism of model structures using hydrological signatures," Hydrology and Earth System Sciences, vol. 17, no. 5, pp. 1893-1912, 2013.

[3] S. Gharari, M. Hrachowitz, F. Fenicia, H. Gao, and H. H. G. Savenije, "Using expert knowledge to increase realism in environmental system models can dramatically reduce the need for calibration," Hydrology and Earth System Sciences, vol. 18, no. 12, pp. 4839-4859, 2014.

[4] H. Gao, M. Hrachowitz, F. Fenicia, S. Gharari, and H. H. G. Savenije, "Testing the realism of a topography-driven model (FLEX-Topo) in the nested catchments of the Upper Heihe, China," Hydrology and Earth System Sciences, vol. 18, no. 5, pp. 1895-1915, 2015.

[5] J. E. Nash and J. V. Sutcliffe, "River flow forecasting through conceptual models part I-a discussion of principles," Journal of Hydrology, vol. 10, no. 3, pp. 282-290, 1970.

[6] M. P. Clark, A. G. Slater, D. E. Rupp et al., "Framework for understanding structural errors (FUSE): a modular framework to diagnose differences between hydrological models," Water Resources Research, vol. 44, no. 12, Article ID W00B02, 2008.

[7] M. P. Clark, D. Kavetski, and F. Fenicia, "Pursuing the method of multiple working hypotheses for hydrological modeling," Water Resources Research, vol. 47, no. 9, Article ID W09301, 2011.

[8] F. Fenicia, D. Kavetski, H. H. G. Savenije et al., "Catchment properties, function, and conceptual model representation: is there a correspondence?" Hydrological Processes, vol. 28, no. 4, pp. 2451-2467, 2014.

[9] H. H. G. Savenije, "HESS opinions 'topography driven conceptual modelling (FLEX-Topo)", Hydrology and Earth System Sciences, vol. 14, no. 12, pp. 2681-2692, 2010.

[10] T. C. Winter, “The concept of hydrologic landscapes," Journal of the American Water Resources Association, vol. 37, no. 2, pp. 335-349, 2001.

[11] D. M. Wolock, T. C. Winter, and G. McMahon, "Delineation and evaluation of hydrologic-landscape regions in the United States using geographic information system tools and multivariate statistical analyses," Environmental Management, vol. 34, no. 1, pp. S71-S88, 2004.
[12] T. Euser, M. Hrachowitz, H. C. Winsemius, and H. H. Savenije, "The effect of forcing and landscape distribution on performance and consistency of model structures," Hydrological Processes, vol. 29, no. 17, pp. 3727-3743, 2015.

[13] R. A. Freeze, "Mathematical models of hillslope hydrology," in Hillslope Hydrology, M. J. Kirby, Ed., pp. 177-225, John Wiley \& Sons, New York, NY, USA, 1978.

[14] T. Dunne and R. D. Black, "Partial area contributions to storm runoff in a small New England watershed," Water Resources Research, vol. 6, no. 5, pp. 1296-1311, 1970.

[15] R. E. Horton, "The rôle of infiltration in the hydrologic cycle," Eos, Transactions American Geophysical Union, vol. 14, no. 1, pp. 446-460, 1933.

[16] T. Dunne, "Field studies of hillslope flow processes," in Hillslope Hydrology, M. J. Kirby, Ed., pp. 227-293, John Wiley \& Sons, New York, NY, USA, 1978.

[17] R. J. Chorley, "The hillslope hydrologic cycle," in Hillslope Hydrology, M. J. Kirby, Ed., pp. 1-42, John Wiley \& Sons, New York, NY, USA, 1978.

[18] D. H. Pilgrim, T. G. Chapman, and D. G. Doran, "Problems of rainfall-runoff modelling in arid and semiarid regions," Hydrological Sciences Journal, vol. 33, no. 4, pp. 379-400, 1988.

[19] C. W. Downer, F. L. Ogden, W. D. Martin, and R. S. Harmon, "Theory, development, and applicability of the surface water hydrologic model CASC2D," Hydrological Processes, vol. 16, no. 2, pp. 255-275, 2002.

[20] R. J. C. Burnash, "The NWS river forecast system-catchment modeling," in Computer Models of Watershed Hydrology, V. P. Singh, Ed., pp. 311-366, Water Resources Publications, Highlands Ranch, Colo, USA, 1995.

[21] D. A. Burns, J. J. McDonnell, R. P. Hooper et al., "Quantifying contributions to storm runoff through end-member mixing analysis and hydrologic measurements at the Panola Mountain Research Watershed (Georgia, USA)," Hydrological Processes, vol. 15, no. 10, pp. 1903-1924, 2001.

[22] A. R. Buda, P. J. A. Kleinman, M. S. Srinivasan, R. B. Bryant, and G. W. Feyereisen, "Factors influencing surface runoff generation from two agricultural hillslopes in central Pennsylvania," Hydrological Processes, vol. 23, no. 9, pp. 1295-1312, 2009.

[23] S. K. Mishra and V. P. Singh, Soil Conservation Service Curve Number (SCS-CN) Methodology, Kluwer Academic Publishers, Dordrecht, The Netherlands, 2003.

[24] K. J. Beven and M. J. Kirkby, "A physically based, variable contributing area model of basin hydrology," Hydrological Sciences Journal, vol. 24, no. 1, pp. 43-69, 1979.

[25] C. Yao, K. Zhang, Z. Yu, Z. Li, and Q. Li, "Improving the flood prediction capability of the Xinanjiang model in ungauged nested catchments by coupling it with the geomorphologic instantaneous unit hydrograph," Journal of Hydrology, vol. 517, pp. 1035-1048, 2014.

[26] H. Xu, C.-Y. Xu, H. Chen, Z. Zhang, and L. Li, "Assessing the influence of rain gauge density and distribution on hydrological model performance in a humid region of China," Journal of Hydrology, vol. 505, pp. 1-12, 2013.

[27] Z. Ren-Jun, “The Xinanjiang model applied in China," Journal of Hydrology, vol. 135, no. 1-4, pp. 371-381, 1992.

[28] R. Zhao and X. Liu, "The Xinanjiang model," in Computer Models of Watershed Hydrology, V. P. Singh, Ed., pp. 215-232, Water Resources Publications, Highlands Ranch, Colo, USA, 1995. 
[29] Y.-L. Chen and J.-T. Han, "Problems on flood forecasting in the semi-arid region," Advances in Water Science, vol. 14, no. 5, pp. 612-616, 2003 (Chinese).

[30] J. R. Craig, G. Liu, and E. D. Soulis, "Runoff-infiltration partitioning using an upscaled Green-Ampt solution," Hydrological Processes, vol. 24, no. 16, pp. 2328-2334, 2010.

[31] A. Basist, G. D. Bell, and V. Meentemeyer, "Statistical relationships between topography and precipitation patterns," Journal of Climate, vol. 7, no. 9, pp. 1305-1315, 1994.

[32] H. Xu and W. Yao, "A numerical study of the Beijing extreme rainfall of 21 July 2012 and the impact of topography," Advances in Meteorology, vol. 2015, Article ID 980747, 12 pages, 2015.

[33] B. Sivakumar, "Dominant processes concept, model simplification and classification framework in catchment hydrology," Stochastic Environmental Research and Risk Assessment, vol. 22, no. 6, pp. 737-748, 2008.

[34] Q. Duan, S. Sorooshian, and V. Gupta, "Effective and efficient global optimization for conceptual rainfall-runoff models," Water Resources Research, vol. 28, no. 4, pp. 1015-1031, 1992.

[35] Q. Duan, S. Sorooshian, and V. K. Gupta, "Optimal use of the SCE-UA global optimization method for calibrating watershed models," Journal of Hydrology, vol. 158, no. 3-4, pp. 265-284, 1994.

[36] M. Shafii and B. A. Tolson, "Optimizing hydrological consistency by incorporating hydrological signatures into model calibration objectives," Water Resources Research, vol. 51, no. 5, pp. 3796-3814, 2015.

[37] National Center of Hydrological Information, Standard for Hydrological Information and Hydrological Forecasting, China WaterPower Press, Beijing, China, 2000 (Chinese).

[38] C. Zhang, R.-B. Wang, and Q.-X. Meng, "Calibration of conceptual rainfall-runoff models using global optimization," Advances in Meteorology, vol. 2015, Article ID 545376, 12 pages, 2015.

[39] G. Whittaker, R. Confesor Jr., M. Di Luzio, and J. G. Arnold, "Detection of overparameterization and overfitting in an automatic calibration of SWAT," Transactions of the ASABE, vol. 53, no. 5, pp. 1487-1499, 2010.

[40] H. V. Gupta, C. Perrin, G. Blöschl et al., "Large-sample hydrology: a need to balance depth with breadth," Hydrology and Earth System Sciences, vol. 18, no. 2, pp. 463-477, 2014. 

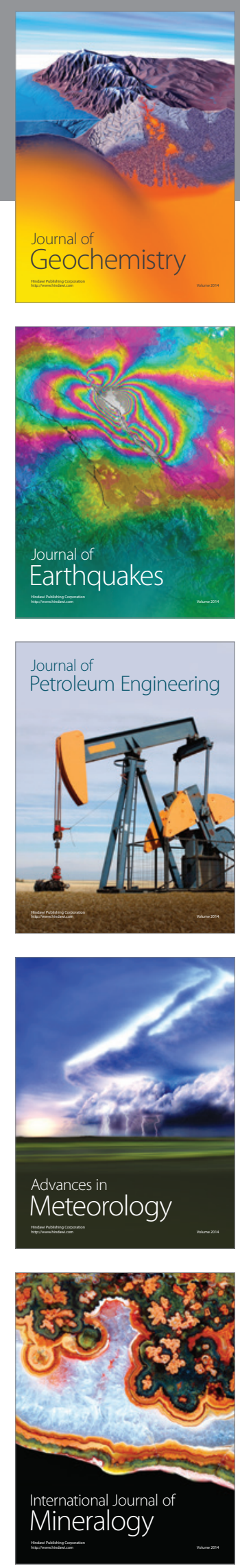
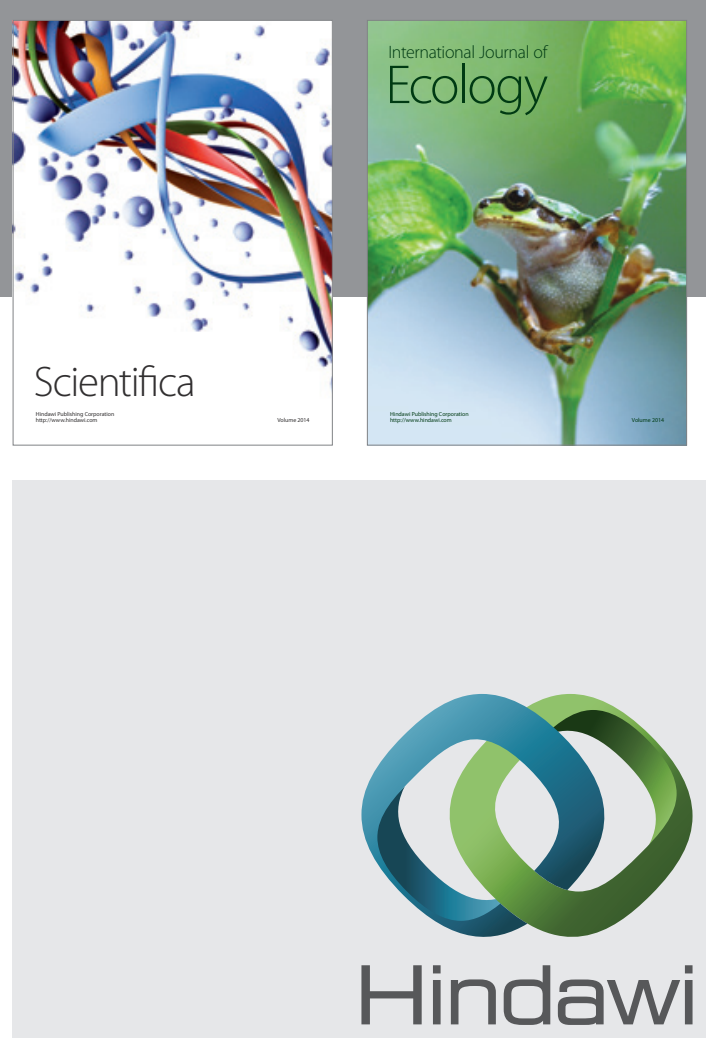

Submit your manuscripts at

http://www.hindawi.com
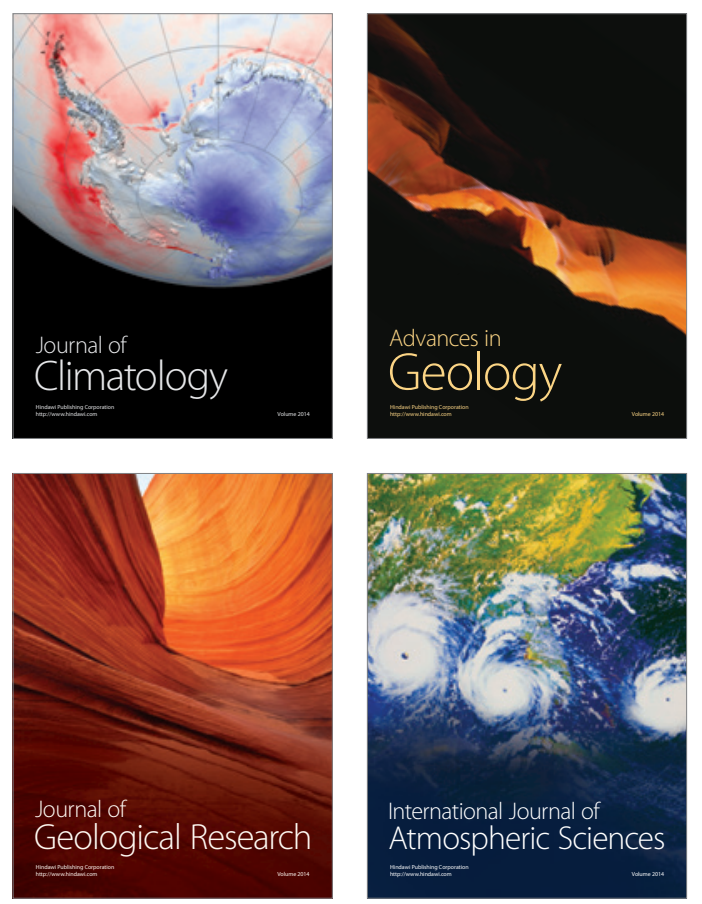

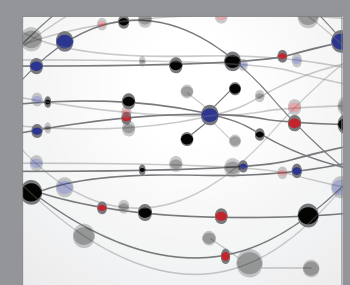

The Scientific

\section{World Journal}
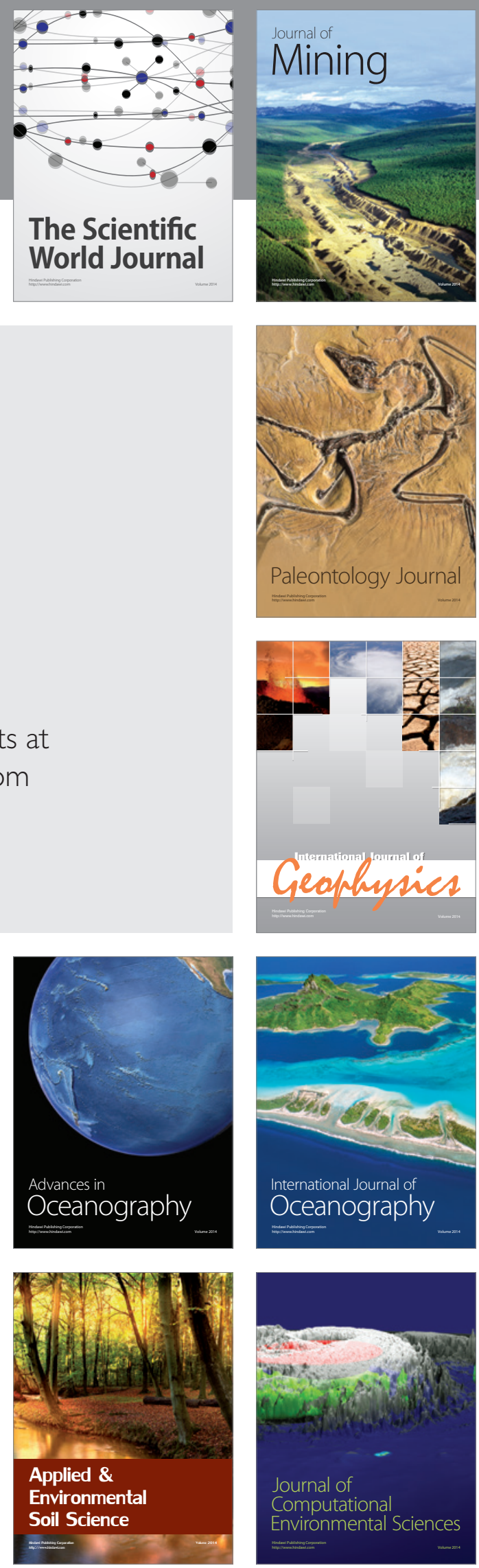